\title{
Using Original Methods in Teaching English Language to Foreign Students (Chinese) in Indian Classroom
}

\author{
Devimeenakshi. K. ${ }^{1}$ \& C. N. Baby Maheswari ${ }^{1}$ \\ ${ }^{1}$ School of Social Sciences and Languages, English Division, VIT University, India \\ Correspondence: Devimeenakshi. K., Asst. Professor, School of Social Sciences and Languages, English \\ Division, VIT University, Vellore-632104, Tamil Nadu, India. E-mail: devimeenakshik@vit.ac.in
}

Received: July 12, 2012 Accepted: August 9, 2012 Online Published: August 10, 2012

doi:10.5539/elt.v5n9p166 URL: http://dx.doi.org/10.5539/elt.v5n9p166

\begin{abstract}
The article gives information on English language teaching schemes in Indian classrooms for foreign students. The teacher monitors as facilitator and instructor. The trainees were trained in the four macro skills, LSRW. I taught some topics in three skills, namely, writing, listening and reading (just three, not speaking skills) to Chinese students in VIT University. The other skill speaking was trained by other teachers among the four. Students were trained to listen to English words and passages, to read the comprehension passages and answer the questions, and to coach basic grammar and revising it. More over, beginners were also guided to learn technical words related to their respective disciplines (major subjects) other than English words. For example, Chinese students posed a query to the faculty to explain on technical words and terms of their main subjects in English, for instance, B.Sc Computer Science (under graduate programme) students wished to learn about the word data. Since, the English Oxford Dictionary meaning is 'facts or statistics used for reference or analysis', but in the field of Computer Science, the word means "information processed by a computer”. So, there arouse a need to help them in distinguishing the different meanings of the word. In addition to, many students were not familiar with English. Thus through the above said way of facilitating, they acquired a good knowledge by varied types of expressions to master their particular subjects. It was a moment to state that they had come from China to India to obtain the nuances of English language. They undertook and were gradually expertised at specific courses in English medium of instruction, perhaps to get degree. Teacher's a few lesson plans (how the practices are conducted in listening, reading and writing skills) as well as some parts in allotted syllabus (listening to songs, passages, writing a paragraph and essay, picture-story writing and write about yourself, reading the passage and writing) were discussed in the current paper. Role of the teacher and student were explained in detail. Therefore, the abstract would portray how the beginners were trained, taught, convinced, persuaded and managed by a tutor to reach the goal of English language teaching to Chinese students.
\end{abstract}

Keywords: innovation, writing, listening, reading, roles of teachers and learners, applications, grammar, humanistic, holistic and heuristic

\section{Introduction}

"Language is a process of free creation; its laws and principles are fixed, but the manner in which the principles of generation are used is free and infinitely varied. Even the interpretation and use of words involves a process of free creation". (Chomsky, 2012)

Being a single source, language, with its complexity, generates communication all around the world. Since it is the method of free creation, the diverse systems of schooling are implemented through this unique cause. Schopenhauer's (2009, p. 5) idea, “The word of man (woman) is the most durable of all material” ensures the quality of teaching Basic English (English Bridge Course) to Chinese students in VIT University. As a matter of fact, any one will be stirred by this attitude and will have authentic interest and pleasure to render service in the institution. The students are coming from China to India especially to study and develop their skills in English language. There are students from Wuhan and Zhen Zhou Universities under Top Up Programme scheme, who were taught English to acquire proficiency in English. Justice was rendered to students in teaching. However, Dewey's (2012) concept “The aim of education should be to teach us rather how to think, than what to think-rather to improve our minds, so as to enable us to think for ourselves, than to load the memory with the thoughts of other men", made me (as an individual not influenced by other men's thoughts) to plan and adopt 
Communicative Language Teaching methodology with power point presentation device. White board and marker pen were also used as a traditional means to communicate distinctly to students creating concrete classroom ambience.

\subsection{Innovation}

Secondly, "Innovation is fostered by information gathered from new connections; from insights gained by journeys into other disciplines or places; from active, collegial networks and fluid, open boundaries. Innovation arises from ongoing circles of exchange, where information is not just accumulated or stored, but created. Knowledge is generated anew from connections that weren't there before”. (Wheatley, 2009)

According to Oxford Advanced Learner's Dictionary, innovation is "the introduction of new things, ideas or ways of doing something" similarly, in the above passage, innovation would mean invention through creation. Innovation in trainer's perspective would denote the recent implemented methods of the trainer. The trainer trained the students with collected data and implemented her own style to train the learner in suitable ways. New things or ideas could be the adopted methods of the trainer. The trainer created new types of exercise and the learner was encouraged to develop his creative activities through lessons. Hence the learner was given practice in new lessons and in doing some kinds of exercises. One illustration for a new exercise would be the pre-listening practice that was discussed below, was not familiar earlier to students. Every exercise in four skills was new to them, perhaps a few might be known to them. They knew English grammar and managed to talk English. They did learn English language in China yet not familiar with language and communication skills. The four teachers trained the trainees to acquire sufficient knowledge in language and communication skills. The acquired skills helped them to prepare and appear for competitive exams.

As a result, the teachers' tireless efforts in executing creative teaching methodologies in LSRW skills allows English to touch the culminating point in the present scenario through English language teaching and the teaching-learning process. The outcome is extremely useful to the current generation to sustain in any industry or multi-national company.

In this paper, some of my innovative techniques in teaching English to Chinese students are advocated. Four members of faculty were allocated to teach English to Chinese students. The course was started from the preliminary level and the plan was to train them fundamentally to learn English language. Thus the syllabus was designed in such a manner as to facilitate them to use English as a tool in their future professional career. In my case, I was given Writing in English (Written English). My task was quite interesting. When I asked them to write simple sentences on the topic, "Write about yourself", every student was asked to write about his/her details in own words. It was a free practice like free writing. In connection to the given exercise, some points were dictated in the class to help the learners. Subsequently they were asked to convert the points into coherent sentences. The given points were:

- Your score/grade

- Your exams - which will you take, for (eg.) IELTS OR GRE

- Your work experience

- Your hobbies and interests

They furnished the required details and thus the teacher enlightened them to give self details. Hence, during interviews they could depict their proficiencies for the job market in future. This exercise was given as an assignment and papers were submitted in proper format (A4 size paper) written or printed copies. Their names and registration numbers (University roll numbers) were mentioned.

In fact, "Effective writing involves conveying a message in such a way as to affect the audience as the writer intends". (Parrott, 2010, p. 211), and reasons for writing are, "for diagnostic purposes, develop linguistic competence, providing practice in aspects of writing skills per se, for example: selecting characteristic features of particular text types according to the purpose in writing, including appropriate stages in the process of composition, assessing the knowledge, assumptions, attitudes and interest of the intended audience and addressing them accordingly" (Parrott, 2010, p. 222)

With reference to the above quotations, another kind of exercise was also offered namely, descriptive type of essay. The students had to write a paragraph on seeing a visualized picture in the classroom through projection and later to write essays so as to strengthen their power of expressions. Even general topics based on the Chinese culture, for example, writing a summary on the significance of Chinese stone lion, were assigned as class work. At this juncture, it would be apt to share the expressions of Vernier, Barbuzza, Giusti, and Moral (2012), "EFL 
teachers' role is to value students' native-language-related rhetorical traditions and guide them through a process of understanding them rather than rejecting students' backgrounds. Hence, culture is at play”. The underlying idea of the quote was that the teachers should understand students' affinity towards their native language, culture and traditional practices. As the title (Chinese stone lion) was related to their own nativity, the very sense inspired them to develop their writing skills. It was an approach in creating interest for writing skill.

\subsection{Interest}

Curiosity is one of the most permanent and certain characteristics of a vigorous intellect. (Johnson, 2012)

Curiosity instigated many learners to know language whole heartedly. Specifically students of that batch were better in thinking, planning and writing. One batch (b-batch) was extremely good at studies. The wonder was, the English language was novel to many Chinese students, but they were hard workers in learning the language and proved to be better than other students. The next practice was story writing, a visual image was displayed, pupils were expected to analyse the picture and simultaneously questioned to do a write up on the given picture. The word limit was about 150 words divided into two paragraphs. The first paragraph had to give the aim of the paragraph/introduction. The second paragraph should state the substance as well as conclusion of the paragraph. A title must be selected as every component of the paragraph would be awarded marks. For example, the title of the paragraph and grammar carried one mark, introduction had two marks and conclusion was allotted two marks. The maximum marks of four was awarded.

\section{Listening Skills}

In the next unit, the concentrated lesson was listening skills, Pree’s (2009) words," a speaker holds a conch shell as a symbol of temporary position of authority. Leaders must understand who holds the conch-that is, who should be listened to and when", in this context, the two noticeable factors are the encoder (sending) and decoder (understanding) and their communication process. The teacher conveyed the message during her class period and students reciprocated in the same period. That is, when the information was communicated, it must be made clear that why and whom it was to be communicated. This process affirmed when students enjoyed English songs and speeches during class periods.

"To listen fully means to pay close attention to what is being said beneath the words. You listen not only to the 'music,' but to the essence of the person speaking. You listen not only for what someone knows, but for what he or she is. Ears operate at the speed of sound, which is far slower than the speed of light the eyes take in. Generative listening is the art of developing deeper silences in yourself, so you can slow our mind's hearing to your ears' natural speed, and hear beneath the words to their meaning." (Senge, 2009)

The given passage clearly depicts the importance of keen listening. Here, the learners were able to recognise some indistinct English words in songs, possibly because of their foreign origin that would be difficult to Indian students. Even, in Wikipedia, free encyclopedia (2012) we can find a message that supports the said view, (i.e.) "in Chomskyan's linguistics, External language (for foreigners, English language is External language) applies to language in social contexts, i.e. behavioral habits shared by a community”. Foreign learners' society and people they met would have influenced them to be familiar with some native speakers' accents and sounds. More over, keen listening allowed them to realise the essence of the words of singer or speaker. Thorough understanding of innate feelings were realised through listening than seeing. In fact, the speed of light (any bright image) is faster than the speed of sound. But sound is more effective than light. Light is just a flash but sound reverberates within oneself. And it is no wonder that listening is the key skill among other skills. Thus the skill is given importance since it leads other skills. Needing to highlight the significance of listening skills several exercises were assigned in the curriculum. Accordingly, some listening tasks and practice were done in classroom and in the English language laboratory. Classroom questions such as, Fill in the blanks, Choose the correct option and One word question were queried to evaluate their listening skills.

Mao Tse-tung's (2009) perception, "We should never pretend to know what we don't know, we should not feel ashamed to ask and learn from people below, and we should listen carefully to the views of the cadres at the lowest levels. Be a pupil before you become a teacher; learn from the cadres at the lower levels before you issue orders" gave a notion that whomever might be would stoop down to gain knowledge and to learn persons. No matter, whether we were students or teachers, we should be like students when we wanted to and would be teachers when needed to. Therefore, it had become essential to listen to the words of students (low cadre) thereby a chance for an individual to improve herself as a teacher (higher cadre). Hence learning process could make us to feel free to learn information. The very attitude in knowing information and people guided me to observe foreigners' easy way of recognising the words of native speakers than Southern region students of Tamil Nadu (Tamil Nadu is a state in India (Indians) who found difficult in identifying the words. In that instant, I realised 
their problem with learning words (vocabulary) in English and writing paragraphs/essays than identifying sounds and words in language. Home-work was given to inspire and assess their skills. It was an approach to improve their language skills in terms of creativity.

Conceivably their assignment tasks in listening exercise(another example, listen to a passage/message) gave an insight to the trainer and her inference was associated with the views of Larry Barker (2009) who knowingly gave his message as, "Effective listeners remember that "words have no meaning - people have meaning." The assignment of meaning to a term is an internal process; meaning comes from inside us. And although our experiences, knowledge and attitudes differ, we often misinterpret each other's messages while under the illusion that a common understanding has been achieved". As a matter of fact, the idea was very clear that students understood the listening exercise with their instinctual knowledge than dictionary meanings. Perhaps the accents allowed them to comprehend the lesson. Despite the search for meanings from dictionary, the trainees attempted the listening exercise. There was no point of understanding thoroughly the content but the ability to find out the answers through words enhanced their sharpness and capacity to identify native speaker's accents and words. Hence, in spite of lacking vocabulary knowledge, they were able to perceive and work.

\subsection{Classroom Task in Listening Skill (One Model)}

1. Audio track was played twice like the notion of Epictetus that, "Nature gave us one tongue and two ears so we could hear (listen) twice as much as we speak” (Kathy, 2005), or once.

2. The material included conversations or messages/news bulletins, for e.g. BBC news

3. The exercise was to fill up the blanks or choose the correct answer.

4. To answer questions, one word answers or writing answers in sentences

The key was displayed for evaluation in terms of self- assessment and self-study. I adopted peer-correction method in a few classes.

\subsection{Teacher's Role in Listening Exercise}

The lecturer allowed the class to listen to the audio track. She is the key motivator to create interest in attentive listening. Authorised and standard materials were used to help students in order to encounter tough competitions. Of course, the tasks were based on exam-oriented and career-oriented lesson plans. Learners underwent lessons for certain purpose. They were given instructions that they could discuss in groups or in pairs to learn and get to know better after completing the class work. Encouragement was given to pay attention during listening sessions in order to attempt questions. While checking and discussing answers they grasped meanings accurately and avoided errors. One audio track was sufficient in assisting them to make out native speakers' words and accents. Students acquired knowledge through given syllabus. The curriculum was designed and devised for the welfare of students. Conversation and dialogues would increase their fondness for vocabulary and right usage of words in English language. The fill in the blanks worksheet allowed them to guess keys. When training listening skill, the trainer spelt words with intonation and stress so that trainees could immediately identify native speakers' style of speaking and practise to talk like them.

- The instructor must take pains and put in efforts to speak slowly.

- It is necessary to use good quality audio tracks and sound systems to avoid chaos and commotion in class.

- Books published from Oxford University Press and Cambridge University Press are recommended to use in teaching English language. There are British English and American English. It is better to use versions of Oxford University press and Cambridge audio tracks for survival of ideal English language through out the world.

\subsection{Students' Job in Listening Exercise}

The learners were asked to listen to the sound tracks and write the answers. And answers not known could be found after listening twice or after discussion. They worked according to the directions of the teacher. With presence of mind they answered some questions and wrote after listening with rapt attention. Sometimes they would be misled by pronunciation or content and in some cases the matter might not be recorded properly. Barriers to communication like, noise during listening practice could also be a hindrance to students.

- Pre-listening task - Before paying attention to a description of the town in which they are studying, students are commanded to make a list of points or say something about the place. As they listen to the narrative they confirm the points which are, in fact, mentioned.

- Students listen to a song and subsequently answer questions (post-listening task) about the environment of the song and tone of the poet. 


\subsection{Application of Listening Skill}

- Listening keenly to the words in presentation

- Increasing memory power and knowledge power

- In maintaining records (after oral-aural summit)

- Stability in storing information

- Expanding the talent in keen notice of foreigners' accents and English words

2.5 Why Are Listening Skills Taught to ESL and EFL Students?

Its applications play as dominant constituents in the career-orientation of novices. Every candidate is a product in any industry and really meant to bring fortune to the firms where one works. All four skills (LSRW) are equally important but listening is the key dexterity forming base in any kind of communication skill. A person develops his perseverance by entering into the depth of listening process to accomplish the objective.

\section{The Significance of Reading Skills}

Reading skills improve concentration and help to continue with stable mind assuring clarity of gaining relevant sense in a piece of work. The two techniques skimming and scanning are efficient criteria to seek the main points and sub-points of reading comprehension text. Every passage has a topic sentence highlighting the theme of the paragraph. Direct and simple language of a transcript will stimulate the reader to read further. Analysing the needs and psychology of audience is essential for a writer and for the reader as well.

\subsection{Role of Teachers and Students}

The students would inquire the teacher about the unknown words. When the reading was done fast the students found difficult in searching for results. Purposely they would try to predict many kinds of data in justifying a short story book. The teaching-learning process of both (teachers and students):

- "Students work out the meaning of selected words and expressions from the context.

- The teacher teaches a few key words.

- The teacher draws attention to some of the grammar in the text.

- $\quad$ Students complete a detailed true/false exercise.

- Students locate topic sentences in some of the paragraphs.

- Students discuss topic related to the content of the text.

- S Students scan the text to pick out proper names”. (Parrott, 2010, p.183)

\section{Grammar}

"A pedagogical grammar is a grammatical description of a language specifically designed as an aid to teaching that language, such as the grammar textbooks used in foreign-language classes or the grammar instruction offered to trainee teachers". (Davies, 2007, p. 2).

Since pedagogical grammar was designed as an aid to teach language, thereby, trainers were at ease to train the trainees. In addition to that, recommended grammar lessons provided good exposure to trainees. The foreign learners had plans to go in for English proficiency tests such as IELTS or GRE. So tutors could train them for these as well as the prescribed curriculum. As one part of the lesson was punctuation, power point presentation tool was utilised, slides were displayed, and marker pen was used to denote punctuation and passages were written on the white board, in the teaching-learning process. The students learnt methodically, indeed it was an interactive session. Sir Ken Robinson’s (2009) saying, "If you're not prepared to be wrong, you'll never come up with anything original" was verified when the beginners had a few doubts and as a result went wrong in the given exercises. Doubts were clarified, in fact, a new light was thrown in English as a foreign language learning programme. Some issues were discussed in terms of awareness and also answered in the class. Thus, "It (syllabus) is intended to assure reliable preparation for students and an orderly, consistent progression from level to level” (Feder, 2008).

\subsection{Part Played by the Teacher and Learner in Teaching-learning Process}

\subsubsection{Student-centred Classes}

The first and foremost priority was always given to students for their well being in the field of studies. Their need was the primary scope of the teacher. Every individual was considered and his/her problems were solved. 
He or she was taken into care. Proper guidance was provided. Self-study was appreciated and encouraged. Self-learning should be the best way of studying to understand the content without ambiguity. If information was imposed or overloaded, the receiver might be confused or bored to pursue with lessons. The main purpose would be satisfied when pupils were made to follow the context and comprehend the content. This type of method was adopted while teaching grammar to students. Since Grammar is a difficult task, students were given extra care. If students could understand, it would be easy. Here, they should be sharp enough to apprehend the rules of varied grammar exercises.

\section{Service of Teaching through Humanistic and Holistic Approaches}

Caring and sharing bond between mother (teacher) and child (student) is ascertained by treating each individual (student) as a "complete" person. The language is inculcated as a only skill and not as assorted or as any definite skill. The linguistic and cross-cultural augmentation are inseparable, inter-linked with one another. The prescribed syllabi is incorporated with linguistic, cross-cultural, communication and other necessary skills. The learners are motivated to test their capacity of learning and plan for action after the self-assessment.

\section{Focusing on Learning than Teaching}

1. Instructors prepare students to find out their inner self

2. Inspiring them to work hard in receiving information through various sources

3. “Talk less and work more”, trainers talk less and trainees work more

4. Self-learning attitude is injected in the minds of the students

5. Hunting for novel ideas

6. Creating new trends and tendencies

7. Supporting to carry out project proposals suitable to core subject

8. Practical way of learning is highly recommended for cross-cultural growth

9. Text book serves as a funnel to pour knowledge into skulls and "learning takes place outside as well as inside of the classroom through continual language practice and cross cultural contact” (Feder, 2008)

The focal point of student-centered learning is to convert the student into nucleus inside the atom. Atom (teacher) will induce the nucleus for its operation. Major consideration for new learners, essential needs of students, educational and cultural backgrounds, distinctive learning modes, and informal situation, circumstances then atmosphere, completely compose the aim of teaching, the result of teaching, the destination of teaching-learning process and the feed back of students. The feedback of teachers and students display the job done by both. Sometimes students feedback may be misleading. As a result, necessary changes due to feedback will not be certain. Hence it is imperative to go for exact feedback of students to plan for correction. So, "A program of teaching should not be a Procrustean bed to which students must conform regardless of their individual needs and predilections, but should be flexible and responsive. Instruction must focus more on students themselves than on the materials of instruction. Textbooks are tools and not the core of a class and should never be allowed to dominate the conduct of a class. We cannot truly "teach" students but only assist them in their learning. The responsibility for learning belongs to the learner. The teacher's role is to be a facilitator and guide who provides "a nurturing context for learning” (H. D. Brown, 1980) and fosters the "learner's feeling of primacy in a world of meaningful action" (Stevick, 1980) (Feder, 2008).

\section{What Is Holistic Learning?}

Holistic learning denotes two aspects, teaching to an entire person (humanistic view), and the combination of talents and matters within a pre-arranged classroom activity. This bi-thought shall complement each other. Neither the learner nor the language can be disregarded in a language classroom in terms of Humanistic approach. But the Holistic approach focuses both on learner and classroom tasks, (i.e.) men and matters. As a matter of fact, "Aiming towards holistic learning requires us to recognize the complex human nature of the learner as well as the intricate, abstruse nature of language as a medium of communication. A communicative, experiential approach promotes interaction between whole learner and whole language. The utilization of theme-based tasks is one way to emphasize the communicative use of language and allows us to present the different threads of language and of culture in a unified, contextualized, integrated manner” (Feder, 2008).

\section{What Is Heuristic Learning?}

Heuristic learning or how to learn is inclined to these forms viz. initiative, innovative, investigative, impulsive and energetic in teaching-learning method. The prototype of heuristic learning is embodied by a basic learner in 
trying to look for a solution to the problem than swallowing the information supplied by the instructor. “Gattegno's Silent Way exemplifies this concept. Concentrating on the work of the learner rather than the performance of the teacher, and seeking to help the learner to develop criteria for language use instead of promulgating rules, this approach focuses on learning how to learn and not the accumulation of discrete facts and pieces of information" (Feder, 2008). A learner gains wisdom by probing into every detail through his self-study and self-discovery. Therefore, equips himself/herself to master any topic which can be carried out by him/her through out his/her career life and personal life to face crisis and to analyse critical situations in future. Some activities like Riddles and puzzles, crossword puzzles, information-gap exercises, mono-act, giving dialogue exercises (spoken), and role-play (single and pair) support heuristic learning. Hence, "Setting up situations from which a student can learn requires more skill and patience than dispensing information, but the rewards are proportionally great. The role of the teacher is to be a guide and to devise effective opportunities for learning” (Feder, 2008).

\section{Conclusion}

This write up sums up the investigation of field work with the result. Each communication skill (L,S,R,W) was guided in the classroom with relevant modus operandi but some parts of listening and reading and a few more parts of writing were assigned to a teacher (me) in the given syllabus. The planned cum prepared lessons facilitated the learners to acquire knowledge and skill, uniquely in English language, during one particular semester in VIT University. Teaching English as a foreign language to students promoted the trainer's skill and increased her patience towards the Chinese students. Students were not able to compete with the pace and style of native speakers due to their low level of understanding in English language. They could identify a few words might be of their foreign origin they handled the tasks. Reading and writing skills' lessons were presented through power point technique so as to grasp the study materials. They didn't attempt to memorise but tried to understand the definition or theorem by referring the Oxford dictionary. Generally, the teaching-learning process between the teacher and student develops three approaches, 1. Humanistic approach, 2. Holistic approach, 3. Heuristic approach to make the language learning procedure simple and direct. Humanistic approach propels the student-centred learning, Holistic approach advocates to identify the complex connection between human (learner) and language tasks in terms of communication. Heuristic learning aims at individual study and analysis rather imposing ideas on pupils. They avoid theory and highlight the practical way of obtaining language skills. These approaches can be put into operation only by teacher-student learning orientation. Thus the roles of teachers and students ensure the purpose of education by working out various assignments and targets of both in English language teaching to attain their goals. Their combination introduced a scheme known as teaching-learning process. Finally English is accepted unanimously as universal language and there is no formal life on earth without English. Therefore, developing new modern teaching methods and updating English language teaching systems is very important for language trainers and trainees.

\section{Recommendations in Teaching English as a Foreign Language}

a) First, we must teach Indian customary teaching practices to the Chinese

b) Next, they may obey and be mentored in an Indian classroom atmosphere

c) It is important to shower kindness on them so as to avoid agitated behaviour from them

d) We ought to speak unhurriedly with accurate accents

e) We need to pronounce words and sentences with stress, intonation and pause gradually, otherwise they shall lose interest to listen

f) They can understand the conveyed message better than giving a lecture in the class through visual devices (power point presentation and over head projection)

g) It is mandatory to have a check with the Chinese biological clock as it differs from Indians

h) The teacher is obliged to talk loudly in the class so that students will not feel sleepy. They are prone to tiredness due to climatic changes

i) Ice-breaking sessions ought to be conducted to avoid inhibition

j) There is a need to make them adaptable to the classroom environment

If Chinese students are trained by the above said recommendations, they will be the initial persons to earn reputation out of their extra ordinary skills. The only truth behind them is hard working and nothing else. Teaching plans and roles of teachers are steps to climb up their career ladders for success. It is a pride to an Indian teacher to teach foreigners English in Indian classroom. 


\section{References}

Barker, Larry. (2009). Quotes on Listening. Retrieved June 28, 2012, from http://www.leadershipnow.com/listeningquotes.html

Burkill, Bob, Eaton, Ray. (2011). Developing Teaching And Learning. New Delhi. Cambridge University Press.

Chomsky, Noam. (2012). A few quotes about Language \& Communication. Retrieved June 27, 2012, from http://www.developingteachers.com/quotes/q1.htm

Davies, Alan, (2007). An Introduction To Applied Linguistics. Edinburg. Edinburg University Press. p. 2.

Dewey, John. (2012). Teaching And Learning. Retrieved June 28, 2012, from http://www.randomterrain.com/favorite-quotes-teaching-and-learning.html

Feder, Mark. (2008). Interlink Curriculum Statement Of Interlink Language Centres. Retrieved July 11, 2012, from http://eslus.com/esl/princ2.htm

Hartmann Campbell, Kathy. (2005). The Life Worth Living Series. Retrieved July 31, 2012, from http://www.hartmann-campbell.ch/en/content/documents/ListenFromYourHeart_000.pdf

Johnson, Samuel. (2012). Samuel Johnson Quotes. Retrieved July 7, 2012, from http://thinkexist.com/quotes/samuel_johnson/

Kudchedkar. (Ed.). (2010). Readings in English Language Teaching in India. Chennai. Orient Blackswan Private Limited.

Parrott, Martin, (2010). Tasks For Language Teachers. Cambridge. Cambridge University Press. pp. 183, 211 \& 222.

Pree, De, Max. (2009). Quotes on Listening. Retrieved June 28, 2012, from http://www.leadershipnow.com/listeningquotes.html

Schopenhauer, Arthur. (2009). Proverbia.Net. Retrieved June 28, 2012, from http://en.proverbia.net/citastema.asp?tematica=692\&page $=5$

Sociolinguistics. (2012). In Wikipedia, the free encyclopedia. Retrieved August 01, 2012, from http://en.wikipedia.org/wiki/Sociolinguistics

Tse-Tung, Mao. (2009). Quotes on Listening. Retrieved June 6, 2012, from http://www.leadershipnow.com/listeningquotes.html

Tudor, Ian, (2001). The Dynamics Of The Language Classroom. Cambridge. Cambridge University Press.

Vernier, Barbuzza, Giusti, Moral. The Five Language Skills in the EFL Classroom. Retrieved July 29, 2012, from http://bdigital.uncu.edu.ar/objetos_digitales/2647/vernieryotrosfivelanguageskills.pdf

Wheatley J. Margaret. (2009). Leadership And The New Science. Quotes on creativity and innovation. Retrieved June 28, 2012, from http://www.leadershipnow.com/creativityquotes.html

\section{Appendix 1}

\section{SYLLABUS COPY}

Course Code - EBC101 (E-English B-Bridge C-Course 101)

Course Title - English Bridge Course for the Chinese

LTPC L- Lecture, T - Theory, P - Practical , C - credit

Theory -10 credits, Practical $-4 / 2=2$ credits $=12$ credits

10 credits $=10$ theory periods, 4 credits (laboratory sessions $-4 / 2=2$ credits $=2$ periods),

totally 12 periods thus 12 credited course

\section{Version No. 1.0}

\section{Course Pre-requisites - English Proficiency Test (Beginners)}

\section{Objectives:}

1. To facilitate the students to use English in day to day practical usage.

2. To make the students appreciate the correct use of vocabulary.

3. To help the students achieve fluency and to gain poise in spoken English. 
4. To enhance writing skills among the students

\section{Expected Outcome:}

- To understand the key skills in English and to use them appropriately in real life situations.

- $\quad$ Students will learn to use English effectively in academic and professional scenario.

\section{Unit No. 1}

Listening

Introduction to Listening skills, Listening to Pronunciation (Consonants \& Vowels), Listening to Vocabularies, Listening to Songs, Passages, Dialogues, Speeches \& Conversations, Listening for Announcements, Specific Information \& Main Ideas

\section{Unit No. 2}

Speaking

Situational Conversation-Meeting, Parting, Daily Activities, Talking About Activities, Meeting At The Airport, Language Learning Problems, A Simple Dialogue, (Friends, Near and Dear), Body Language - Structural Conversation: (Simple Questions and Negatives, Short Answer Interrogative Words, Irregular Verbs, Comparisons, Two-Word Verbs, Conversation Drill. - Speaking Activities: Extempore, Debate, Role Play, Addressing The Audience (Welcome Address \& Vote Of Thanks),Talk About Countries, Nationalities, Habits, Routines, Personal Details, Jobs, Likes and Dislikes, Possessions, Leisure Time Activities, Food and Drink, Requests, Future Plans, Past Experiences ,Describe Places, Houses, People

Unit No. 3

Reading

Skimming the Text, Scanning the Text, Reading for Vocabulary, Reading for Pleasure, Central Idea, tone and Intention, Strategies for Reading Comprehension, Reading a Content and Retelling/Writing, Reading at Sentence and Paragraph Level, Reading Stories for Specific Information

\section{Unit No. 4}

\section{Writing}

Write About Yourself, Letter Writing, Composing e-mails, CV, Developing The Hints, Paragraph Writing, Picture Story Developing, Essay Writing, Dialogue Writing, Use Capitalization and Punctuation Correctly, Write a Story, Process \& Product Description

\section{Unit No. 5}

Grammar and Vocabulary

Parts Of Speech, Tenses, Voices, Concord, Phrasal Verbs, Question Tags, Punctuation, Conditionals, Use of Modals, Sentence Patterns. Root List, Word Cluster, Migratory Words, Phobias and Manias, -isms , Main Words and Root Words Based on Core Subjects, Essential English Words and phrases, Develop a Strategy Learning/Recording Vocabulary, Recognize and Use High-Frequency Words and Expressions, Commonly Confused and Misused Words

\section{Text Books}

1. Enhance Your English Skills (Starter) - New Century Book House

\section{References}

1. Essential Grammar in Use; Cambridge University Press

2. Rapid Vocabulary Builder; Goodwill Publication

3. Reading between the lines: Integrated Language and Literature activities ; Cambridge University Press

4. Academic Writing-A practical guide for students; Routledge Falmer

Mode of Evaluation Continuous Assessment (Quizzes, CATs (C-Continuous, A- Assessment, T-Tests), Assignments, etc.) and TEE (T-Term-E-End, E- Examination)

Recommended by the Board of Studies on 11-11-2010

Date of Approval by the Academic Council 30-11-2010

Proceedings of the 21st Academic Council of VIT [30.11.2010] 429 
Please Note: Italicised-bold titles (lessons) are taught and done as Indian classroom exercises with original methods

\section{Appendix 2}

\section{LESSON PLAN}

- Lesson plan - with reference to the article

- Specification of lesson plan (with reference to suggestion)

\section{Writing skills}

- $\quad$ Lesson plan -1 -Write about yourself (20 minutes)

Give your details (name, qualification, from which place/country, name of your educational institution, your exams, your scores, your working experience in any industry/firm/institution, your aim, your presentation (in conference)/project, hobbies and sports)

- $\quad$ Story writing visual picture(s) - internal choice - to write a write up either on first picture or on second picture (30 minutes)

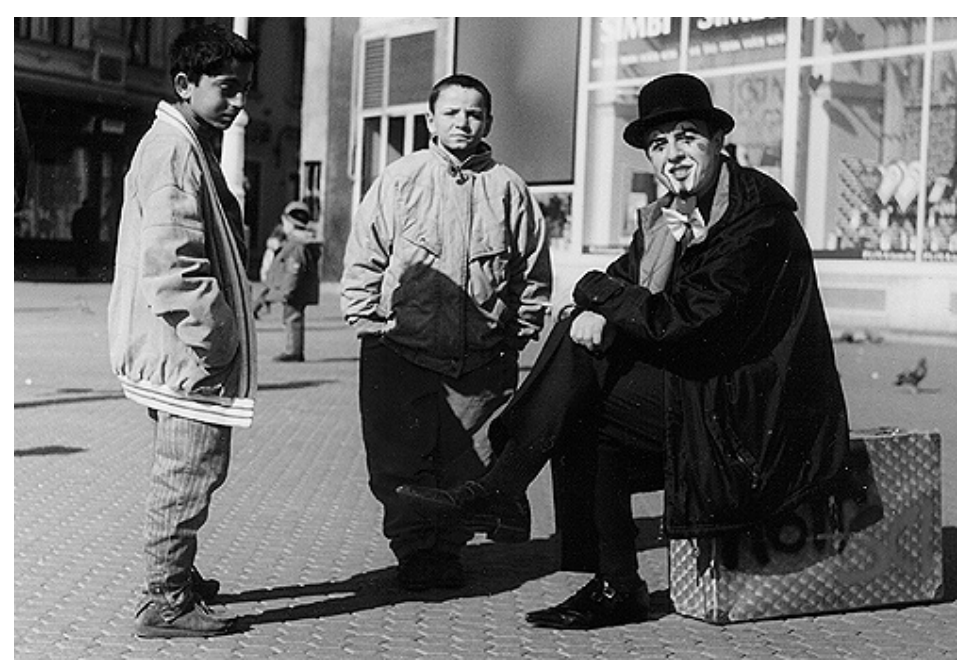

OR

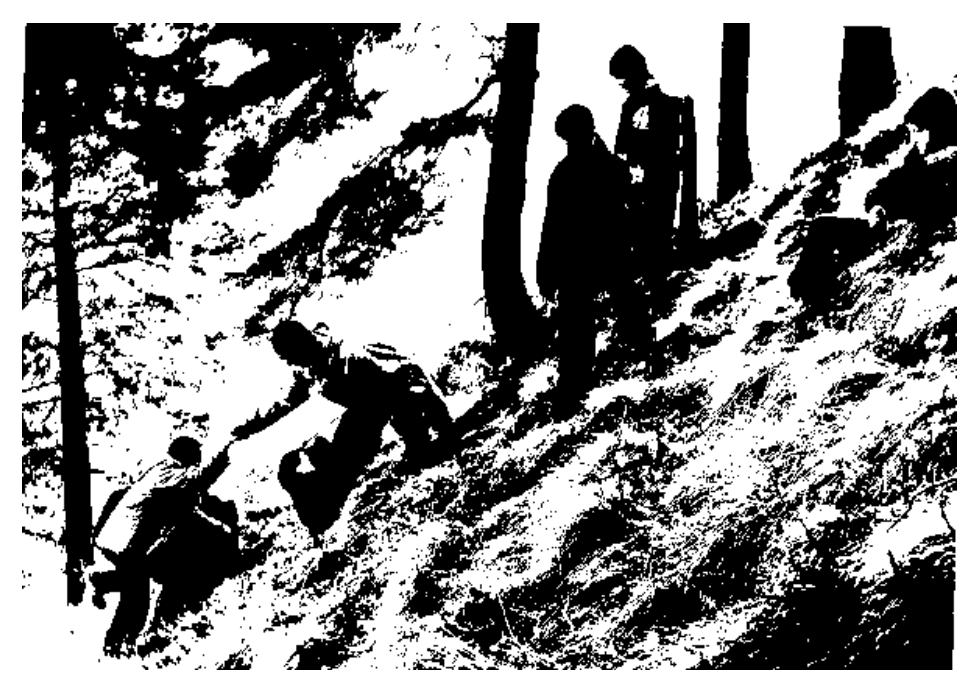




\section{Questions:}

1. See the picture

2. Analyse the picture and give a suitable title to the chosen picture

3. Write a paragraph on any one of the given pictures in about 150 words

4. Write the aim of story writing (introduction)

5. Give details and conclude your paragraph

\section{Listening skills - post listening tasks and pre-listening task}

1. Listen to songs and do the exercises (15-20 minutes)

a. $\quad$ Listening song 1 - Elton John mp3pro 3 December, 2002 (given exercises - choose the correct option and one word question)

b. $\quad$ Listening song 2 - Michael Jackson, greatest hits, history, volume 1 (given exercise - fill in the blanks (oral or written) can be assigned)

2. Listen to passage/message and do the exercises (15-20 minutes)

a. $\quad$ Listening message/passage 1- Vlc mp3 (\$100 laptop for world's poor children) (given exercise - one word answer or write answer in one sentence)

b. Listening passage 2 - BBC learning English activity (Fill in the blanks and choose the correct answer)

3. Listen to conversation/BBC news bulletin (15-20 minutes)

a. Learner-contracts-conversation - Learn English Professionals - British Council/Professionals (given exercise - one word answer or write answer in one sentence)

b. Home work - instructed to listen to BBC news bulletin

4. The description of places was delivered by the teacher (Pre-listening) (30 minutes)

a. Students were questioned to say some points on India.

- $\quad$ Special features of India

- Unity in diversity

- Indian food

- India's customary practice

- Tradition and heritage

b. They were asked to list out their points on Vellore, Tamil Nadu, India (the place where they were studying in), the following points were expected from the learner,

- $\quad$ VIT University

- Historical place

- $\quad$ Sepoy (soldier) mutiny

- $\quad$ Christian Medical College (CMC)

- $\quad$ Vellore jail

- $\quad$ Vellore fort

- Chinese restaurant

Due to time constraint either first question or second question may be asked.

\section{Reading skills}

a. Any reading content (a passage describing a process or narrating an information/story was given to do skimming and scanning processes (20 minutes)

b. Home work - advised to read/learn novels and short story books thus encouraged them in giving instruction such as, 'reading is for pleasure'

\section{Grammar}

a. Parts of speech (using noun and verb forms in sentences or paragraphs) (one period - 50 minutes/60 
minutes)

b. Punctuation (how and where to use punctuation) (one period - 50 minutes/60 minutes)

Websites:

a. http://www.tigurl.org/images/tiged/docs/activities/341.pp (Picture development)

b. http://www.myplick.com/view/4oMWffp7sGx/Capital-Letter-Punctuation-ppt (Capitalisation and punctuation)

c. http://as3v1olet.files.wordpress.com/2008/03/the-basic-in-grammar.ppt (The basic in grammar)

d. http://grammar.ccc.commnet.edu/grammar/ppt/parts.pps (Parts of speech)

e. http://www.rhlschool.com/read5n3.htm (Reading comprehension-one model)

f. www.britishcouncil.org/learningenglish (3(a). Listening)

g. bbclearningenglish.com (2(b). Listening) 